\title{
ENTRE AUSÊNCIA DE DOENÇA E CUIDADO POSSÍVEL: A SAÚDE SEGUNDO USUÁRIAS DA ESTRATÉGIA SAÚDE DA FAMÍLIA
}

\author{
BETWEEN THE ABSENCE OF ILLNESS AND POSSIBLE CARE: HEALTH ACCORDING \\ TO FEMALE USERS OF THE FAMILY HEALTH STRATEGY PROGRAM
}

\author{
Lilian Miranda ${ }^{1}$, Luciana Janeiro Silva ${ }^{2}$, Yasmim Furtado de Souza ${ }^{2}$
}

${ }^{1}$ Fundação Oswaldo Cruz, Escola Nacional de Saúde Pública Sergio Arouca, Rio de Janeiro, RJ, Brasil.

$<$ limiranda78@hotmail.com>

${ }^{2}$ Universidade Federal Rural do Rio de Janeiro, Programa de Pós-Graduação em Psicologia, Rio de Janeiro, RJ, Brasil.

Resumo O artigo apresenta sentidos que usuárias da Estratégia de Saúde da Família atribuem à saúde e sua relação com o cuidado. Utilizou-se o método qualitativo, tomando-se como referencial teórico as discussões de Canguilhem e Winnicott acerca da noção de saúde, bem como apontamentos sobre medicalização da vida. O trabalho de campo foi desenvolvido por meio de entrevistas em profundidade entre maio e julho de 2015 com usuários da Estratégia de Saúde da Família e tratado pela análise hermenêutica. A saúde, relacionada tanto à ausência de doença e ao completo bem-estar, quanto à disposição para enfrentar os sofrimentos inerentes à vida. Coexistem a confiança incondicional na tecnologia médica e a aposta em modos de cuidado intuitivos ou oriundos de relações sociais. O serviço de saúde contribui com o acesso ao tratamento e, simultaneamente, reforça a aposta na prevenção de todos os infortúnios do corpo, bem como a ideia de que o direito à saúde é correlato à responsabilização individual de mantê-la perfeita. Numa cultura marcada pelo individualismo e competitividade, indivíduos que vivem em contextos de profundas injustiças sociais submetem-se a regras de prevenção do risco de adoecer, mas são restritas suas possibilidades de criação de modos singulares de fruição da vida.

Palavras-chave saúde; cuidado em saúde; usuários de serviços de saúde.
Abstract This article presents meanings that women users of the Family Health Strategy program attribute to health and its relation to care. The qualitative method was applied, using as a theoretical reference the discussions of Canguilhem and Winnicott on the notion of health, as well as notes on the medicalization of life. The fieldwork was developed through in-depth interviews between May and July 2015, with users of the Family Health Strategy program, and was treated with a hermeneutical analysis. Health, related both to the absence of illness and to complete well-being, as well as to the disposition to face the sufferings inherent to life. There is a coexistence between the unconditional trust in medical technology and a wager on intuitive care modes or those originated from social relationships. The health service contributes to the access to the treatment and, at the same time, reinforces the commitment to the prevention of all the misfortunes of the body, as well as the idea that the right to health care is related to the individual responsibility to keep it perfect. In a culture marked by individualism and competitiveness, individuals living in contexts of deep social injustice submit to rules to prevent the risk of becoming ill, but their possibilities of creating unique ways of enjoying life are restricted.

Keywords health; health care; health care users. 


\section{Introdução}

A Estratégia de Saúde da Família (ESF), considerada como porta de entrada ao Sistema Único de Saúde (SUS) e como responsável pela coordenação da oferta integrada de cuidados ao longo de toda a vida dos cidadãos (Brasil, 2012), enfrenta desafios tão grandes quanto a abrangência de seus objetivos. Importantes contradições são impostas, na medida em que se almeja a formação de coletivos e sujeitos autônomos, capazes de construir uma clínica ampliada, sensível às dimensões biológicas, sociais, psíquicas e intersubjetivas do processo saúde-doença (Campos, 2006). Entretanto, o cotidiano do trabalho é compartilhado com profissionais e usuários que, concretamente, vivem numa sociedade caracterizada pelo individualismo, alta competitividade, culto da imagem, enaltecimento do consumo e da acumulação (de bens, capital e poder) e, consequentemente, pela banalização do sofrimento e da dor (Luz, 2013). Trata-se de uma sociedade em que predomina a razão instrumental, materializada na valorização da eficiência ou dos fins, sem análise crítica dos meios ou processos de produção de bens e de sujeitos. Por meio dela, todo pensamento, "cegamente pragmatizado" (Horkheimer e Adorno, 1989, p. 69), almeja a dominação e controle racional do ser humano e da natureza.

Nesse contexto, é inevitável a distância entre o sistema de saúde idealizado e o modo como os sujeitos viabilizam sua existência, operacionalizando a gestão e a atenção através do manejo de recursos e problemas que vivenciam, desestabilizando as diretrizes previamente formuladas. No que diz respeito aos modos de uso do sistema, encontra-se, nos textos normativos, certa suposição de que o usuário da ESF é adaptável às prescrições e técnicas de prevenção, podendo, desde que bem informado, buscar tratamento de acordo com os trajetos pré-determinados nas redes de saúde. Porém, a vida cotidiana mostra-se mais complexa, na medida em que os sujeitos, atravessados por sentimentos, desejos, capacidades de protagonismo e ambivalências, materializam distintos modos de acesso e uso dos serviços, configurando o que Cecílio (2012, p. 287) denomina "regulação leiga". Esta não se impõe à gestão formal da rede, mas também não é totalmente controlável ou subordinável, porque o usuário sempre se coloca, em certa medida, como "fabricador" (Cecílio et al., 2014, p. 56) de seu trajeto de busca por cuidados e de utilização de serviços, fazendo bricolagens com os recursos acessados no campo da saúde e em outras instâncias sociais.

Além das ofertas de serviços e recursos, um dos aspectos que influencia tal fabricação consiste nos sentidos que os sujeitos atribuem à saúde e ao cuidado. Estudos que abordam essa temática mostram que é predominante, entre os usuários da ESF, a associação entre saúde e ausência de doença, denotando forte influência do modelo biomédico. Por outro lado, algumas pes- 
quisas identificaram compreensões mais abrangentes a respeito do processo saúde-doença, levando em consideração fatores sociais, familiares, afetivos, econômicos, comportamentais e biológicos. Observam-se, assim, movimentos de resistência dos usuários frente ao poder biomédico e às barreiras de acesso (Silva, Andrade e Bosi, 2014). Do mesmo modo, constatam-se reivindicações pela legitimidade daquilo que identificam como necessário para si mesmos (Souza et al., 2008), ou de usos singulares da prescrição médica, pautados no saber intuitivo sobre a própria condição de saúde-doença (Coutinho e Souza, 2012; Ferrer et al., 2011).

Essas pesquisas contradizem certa tendência de profissionais a representarem os usuários do SUS, predominantemente, a partir de imagens e adjetivos ligados à submissão e inferioridade. Estas, em geral, são traduzidas pela carência de condições básicas de vida e desconhecimento não apenas sobre a saúde, como também acerca da rede de serviços públicos (Loyola, 2013). Concomitantemente, tais estudos indicam a complexidade de se compreender o que é a saúde para os diferentes atores os quais a experimentam e dela tentam cuidar, corroborando o entendimento de que se trata de um fenômeno marcado por diferentes sentidos, indutores de uma multiplicidade de experiências (Birman, 1999).

Essa discussão não pode deixar de ser colocada para o campo da ESF, cuja cobertura nacional é estimada, atualmente, como de 65\% (Brasil, 2017), com atribuições que, como sabemos, estendem-se da prevenção e promoção de saúde, ao controle de epidemias e acompanhamento de várias linhas de cuidado. Considerando a abrangência dessas práticas, este estudo questiona quais os sentidos acerca da saúde e seu cuidado os usuários da ESF vêm construindo a partir do encontro entre aquilo que lhes é ofertado e as formas singulares de receberem e utilizarem tais ofertas para lidar com as experiências de sofrimento e adoecimento.

Partindo de tais indagações, o presente artigo expõe os resultados de uma pesquisa cujo objetivo foi estudar o modo como usuários da ESF significam saúde e práticas de cuidado, discutindo seus diferentes entendimentos e representações, bem como a relação destes com a oferta e apropriação do cuidado. Acredita-se que tal conhecimento pode contribuir com uma reflexão sobre políticas e práticas de saúde mais sensível à experiência cotidiana dos usuários e, portanto, mais aberta às contribuições do "saber leigo" (Cecílio et al., 2014, p. 54).

\section{Narrativas e vida e construção de diálogos com usuárias da ESF}

Esta pesquisa utilizou o método qualitativo na modalidade de "narrativas de vida" (Azevedo, 2014; Bertaux, 1997; Lévy, 2001) e foi sustentada no paradigma construtivista. Este concebe a existência de múltiplas realidades 
socialmente construídas (não governadas por leis naturais), bem como a definição da verdade a partir de consensos. O referido método inclui, também, a interação e reconstrução mútua entre objeto, investigador e realidade (Denzin e Lincoln, 1994). Trata-se de um trabalho que leva o entrevistado a rememorar e contar sua história tal como a elabora no momento do encontro com o pesquisador. Para tanto, este utiliza um tipo especial de entrevistas, caracterizada por um roteiro de questões bastante abertas e flexíveis, capazes de despertar reminiscências numa temporalidade e organização lógica, definidas pelo próprio sujeito de pesquisa (Bertaux, 1997).

O trabalho de campo foi desenvolvido em duas etapas. Na primeira delas, realizada no mês de maio de 2015 por duas pesquisadoras, foram entrevistados, individualmente, doze sujeitos, em dois ou três encontros, de duração média de 1 hora e meia cada um, sendo todos audiogravados e transcritos. Vale ressaltar que seis sujeitos foram entrevistados por uma pesquisadora e seis, por outra. Os temas abordados no roteiro das entrevistas envolviam vivências do cotidiano; relações familiares e sociais; vida laboral; problemas e preocupações gerais; formas de representação de estados saudáveis; modos de cuidado da saúde; problemas de saúde; percursos de cuidado e tratamento; diferentes tipos de recursos entendidos como fonte de apoio ou ajuda no cuidado com a saúde.

Após a escuta das gravações e leitura das transcrições, estas foram transformadas em narrativas, procurando apresentar o fluxo de ideias, descrições de acontecimentos e afetos dos sujeitos da pesquisa, segundo o que foi possível compreender e organizar num formato de texto (Onocko-Campos, 2011). Tais narrativas foram construídas sempre pela pesquisadora que conduziu a entrevista e revistas pela outra pesquisadora que, conhecedora do campo de estudo, apontava aspectos de difícil compreensão ou muito diferentes dos modos de expressão das entrevistadas.

A segunda etapa do trabalho de campo foi desenvolvida em julho de 2015. Para dar continuidade ao processo de construção do material empírico e, ao mesmo tempo, submeter a narrativa escrita à avaliação das entrevistadas, as pesquisadoras voltaram até as casas das depoentes para lê-la. Com isso, as entrevistadas puderam indicar equívocos de entendimentos, acrescentar outros modos de narrar, e julgar certos acontecimentos de suas vidas e construir novos sentidos, a partir daquilo que ouviam.

O diálogo proporcionado nesses encontros foi acrescentado às narrativas, aprofundando-as. O material advindo do campo empírico foi então tratado por meio da Análise Hermenêutica (Gadamer, 1997), que se desenvolve de modo contínuo e dialético, a partir de processos em que o pesquisador busca compreender os sentidos produzidos e explicitados pelos sujeitos de pesquisa. Estes são considerados seres históricos, cuja narrativa é delimitada no tempo e no espaço em que foi construída, sendo necessário conceber o contexto dessa 
produção e as tradições que a sustentam. Tal contexto permanece como um 'pano de fundo' durante toda a pesquisa, porque o objeto não é dele recortado, mas destacado. Para empreender esse processo de análise, após sucessivas leituras das narrativas dos sujeitos da pesquisa, foram construídos núcleos de sentido (Onocko-Campos, 2011) a partir da identificação dos aspectos mais enfatizados e problematizados por eles. Em seguida, estes aspectos foram comentados a partir de autores que abordam a questão da definição de saúde (Canguilhem, 2005; 1978 e Winnicott, 2005; 1975) e discutem a relação dessa temática com as formas de cuidado valorizadas na sociedade contemporânea (Rose, 2007; Conrad, 2007; Caponi, 2009, Czeresnia, 2009).

O referencial teórico da pesquisa pauta-se, principalmente, nas elaborações de Georges Canguilhem acerca do conceito de saúde. Para o autor, a vida humana não pode ser compreendida como um simples somatório de fenômenos neuroquímicos, físicos e eletromagnéticos. Ela se traduz pelo valor inscrito no organismo, como se observa, por exemplo, quando um indivíduo procura o médico. O que o motiva não é a alteração de um processo químico em seu corpo, mas o sofrimento dele advindo, ou a valoração negativa que este impõe à parte da vida (Bezerra Junior, 2006).

Canguilhem (2005) defende que a saúde é um conceito de difícil sistematização e, ao mesmo tempo 'vulgar', na medida em que sua vivência se encontra ao alcance de qualquer ser humano. Ela envolve a possibilidade de adoecer, pois corresponde à "unidade espontânea das condições de exercício da vida. (...) Esse exercício (...) funda (...) e contém (...) o risco do insucesso, risco do qual nenhum status de vida socialmente normalizada pode preservar o indivíduo." (Canguilhem, 1978, p. 62). Envolve, ainda, a sensação de que pode ultrapassar as capacidades do corpo, colocá-lo em teste, sendo vivenciada como um "luxo biológico". Trata-se de uma espécie de "margem de tolerância" que o indivíduo tem em relação às "infidelidades do meio". Uma restrição nessa margem, entendida como diminuição da capacidade de produzir normas de vida, provoca-lhe sofrimento, "sentimento de vida contrariada", sendo este o estado correspondente à patologia (Canguilhem, 1978, p.158). Por outro lado, a ampliação da possibilidade de produzir normas de vida é valorada positivamente, correspondendo à saúde. Note-se que, necessariamente, o reconhecimento da saúde ou da doença envolve um julgamento de valor, o qual, na segunda, é negativo.

Para discutir as noções de saúde e doença, Canguilhem $(1978 ; 2005)$ utilizase de exemplos prioritariamente da vida orgânica, mesmo enfatizando que esta é sempre fruto de um processo de valoração. Neste artigo, considerando a complexidade inerente ao trabalho com valores, optou-se por associar tais discussões a uma concepção de saúde advinda de pesquisas que têm o mundo (inter)subjetivo no centro de suas preocupações e que também atribuem importância ao potencial de criação do ser humano. Para tanto, as pesquisadoras 
apoiaram-se na concepção de saúde elaborada por Donald Winnicott, autor que fundamenta sua obra na teoria psicanalítica, bem como na sua experiência de pediatra e psicanalista. Winnicott dirige-se, em vários momentos, a enfermeiros, assistentes sociais e à sociedade em geral, para explorar suas concepções acerca do cuidado e das formas não especializadas de exercê-lo.

Em consonância com o que foi visto em Canguilhem, também para Winnicott, a saúde é reconhecida a partir de um julgamento de valor porque se encontra relacionada, necessariamente, à capacidade do sujeito de sentir a vida como algo a ser criado. Ainda que o reconhecimento do outro e a interdição à onipotência sejam parte essencial do desenvolvimento emocional de cada indivíduo, sua saúde está relacionada à possibilidade de experimentar a própria existência como real e singular. Assim, saúde aproxima-se mais da sensação de que a "vida é digna de ser vivida" (Winnicott, 1975, p. 95), do que da submissão a regras de bem viver.

Qualquer tipo de julgamento é influenciado pelo meio sociocultural dos indivíduos, dependendo de relações intersubjetivas. Sendo assim, as definições de saúde guardam a marca dos ideais e das condições concretas de vida de uma sociedade. Partindo desse referencial teórico, pergunta-se: Quais os sentidos de saúde para usuários da Estratégia de Saúde da Família?

Todo o processo de pesquisa foi aprovado pelo Comitê de Ética em Pesquisa da Escola Nacional de Saúde Pública Sergio Arouca (protocolo 1.027.309) e todos os sujeitos assinaram o termo de Consentimento Livre e Esclarecido, de acordo com a Resolução n. 466/12 do Conselho Nacional de Saúde.

\section{Sujeitos e campo de pesquisa}

Os sujeitos da pesquisa foram 12 usuárias de seis equipes de uma Clínica da Família (CF) da cidade do Rio de Janeiro. A ESF foi escolhida como campo de pesquisa por se tratar do serviço que, potencialmente, tem maior proximidade com as pessoas que precisam fazer algum tratamento contínuo. A CF a qual os entrevistados estão adscritos fica numa área da cidade com alto índice de violência e criminalidade, índice de desenvolvimento humano de 0,75 e cobertura da saúde da família de 13,58\% (Prefeitura do Rio de Janeiro, 2018), configurando-se como uma região bastante vulnerável.

Nenhuma condição de saúde ou hipótese diagnóstica dos sujeitos foi tomada como critério de inclusão. Apenas não deveriam ser indicados usuários que, no período destinado à realização das entrevistas, estivessem vivenciando alguma situação de crise de saúde ou aqueles que não desejassem participar. As pesquisadoras delimitaram, ainda, que todos os participantes fossem adultos, com idade mínima de 18 anos e máxima de 65, e estivessem em acompanhamento na CF por, no mínimo, um ano. 
Para a definição das pessoas a serem entrevistadas, o projeto de pesquisa foi discutido numa reunião com todos os profissionais da unidade. Em seguida, as pesquisadoras solicitaram a indicação de dois usuários de cada uma das sete equipes que compõem a Clínica. Considerando que o fato dos sujeitos pertencerem a um mesmo território, adscrito pela Clínica, permitia certa homogeneidade das condições sociais, sanitárias e culturais, não foram estipulados quaisquer critérios de escolha, além daqueles acima mencionados. Sugeriu-se, apenas, que fossem indicados usuários os quais possuíssem alguma questão ou curiosidade relacionada à temática saúde e cuidado.

Os agentes de saúde marcaram as entrevistas e conduziram as pesquisadoras à casa dos sujeitos, onde todos os encontros foram realizados. Ao explicar os motivos pelos quais escolheram aqueles usuários, comentaram que, em geral, eram pessoas que precisavam muito ser ouvidas. Os agentes selecionaram pessoas que cuidavam de familiares com problemas mentais, outras que, aos olhos desses profissionais pareciam 'esquisitas' outras que lhes demandavam excessivamente, imprimindo a sensação de que nada do que fizessem responderia às suas necessidades. Não justificaram o fato de terem identificado apenas usuárias do sexo feminino.

O Quadro 1 apresenta algumas das características gerais das entrevistadas, cujos nomes são fictícios:

Quadro 1

\begin{tabular}{|c|c|c|c|c|}
\hline \multicolumn{5}{|c|}{ Características das entrevistadas } \\
\hline Nome & $\begin{array}{l}\text { Estado } \\
\text { civil }\end{array}$ & Ocupação & Idade & $\begin{array}{l}\text { Acompanhamento em } \\
\text { saúde }\end{array}$ \\
\hline Pérola & Separada & $\begin{array}{l}\text { Diarista. Também possui um bazar em sua } \\
\text { casa, onde vende roupas, sapatos, acessórios, } \\
\text { alguns dos quais confeccionados por ela } \\
\text { mesma. }\end{array}$ & 37 & $\begin{array}{l}\text { Não refere nenhuma } \\
\text { condição crônica. } \\
\text { Acompanha seus filhos nas } \\
\text { necessidades em saúde. }\end{array}$ \\
\hline Safira & Casada & $\begin{array}{l}\text { Do lar. Saiu de seu emprego para cuidar do } \\
\text { filho. }\end{array}$ & 36 & $\begin{array}{l}\text { Dedica-se integralmente } \\
\text { aos cuidados do filho } \\
\text { autista. }\end{array}$ \\
\hline Cristal & Casada & $\begin{array}{l}\text { Do lar. Cuida dos netos sob sua } \\
\text { responsabilidade. }\end{array}$ & Sem inf. & Refere ser hipertensa. \\
\hline Turquesa & Separada & $\begin{array}{l}\text { Do lar. Trabalhou como auxiliar de serviços } \\
\text { gerais, mas optou por pedir demissão e } \\
\text { realizar obra em sua casa com o dinheiro da } \\
\text { rescisão. }\end{array}$ & 52 & $\begin{array}{l}\text { Não realiza } \\
\text { acompanhamento regular } \\
\text { em saúde. Busca os serviços } \\
\text { da CF de acordo com as } \\
\text { demandas que surgem. }\end{array}$ \\
\hline Esmeralda & Casada & $\begin{array}{l}\text { Do lar. Trabalhou por anos como diarista e } \\
\text { aguarda aposentadoria. Deixou de trabalhar } \\
\text { fora devido a problemas de saúde. Cuida do } \\
\text { filho com esquizofrenia. }\end{array}$ & Sem inf. & $\begin{array}{l}\text { Refere ser cardíaca } \\
\text { e hipertensa; realiza } \\
\text { acompanhamento regular. }\end{array}$ \\
\hline Angelita & Separada & $\begin{array}{l}\text { Do lar. Realiza serviços temporários de vez } \\
\text { em quando. }\end{array}$ & 41 & $\begin{array}{l}\text { Não realiza } \\
\text { acompanhamento regular } \\
\text { em saúde. Busca os serviços } \\
\text { da CF de acordo com as } \\
\text { demandas que surgem. }\end{array}$ \\
\hline Coralina & Separada & $\begin{array}{l}\text { Cuidadora de crianças. Tem uma creche que } \\
\text { funciona em sua casa. }\end{array}$ & 55 & $\begin{array}{l}\text { Diabética e hipertensa, } \\
\text { realiza acompanhamento } \\
\text { regular. }\end{array}$ \\
\hline Jade & Casada & $\begin{array}{l}\text { Comerciante. Tem um bazar de venda de } \\
\text { roupas de criança no quintal de sua casa }\end{array}$ & 42 & $\begin{array}{l}\text { Tratou-se de câncer no } \\
\text { colo do útero, faz revisões } \\
\text { regulares no INCA. }\end{array}$ \\
\hline
\end{tabular}


Continuação Quadro 1

\begin{tabular}{|c|c|c|c|c|}
\hline \multicolumn{5}{|c|}{ Características das entrevistadas } \\
\hline Ágata & Casada & $\begin{array}{l}\text { Costureira. Cuida também da casa e auxilia } \\
\text { no cuidado dos netos. }\end{array}$ & 45 & Pressão alta e depressão. \\
\hline Rosa & Casada & $\begin{array}{l}\text { Cuida da casa, da sogra e da filha, que } \\
\text { possuem necessidades de acompanhamento } \\
\text { contínuo, para diferentes tarefas do dia a dia. }\end{array}$ & 48 & $\begin{array}{l}\text { Recorre à clínica para } \\
\text { acompanhamento clínico } \\
\text { da sogra (que possui } \\
\text { Alzheimer) e quando } \\
\text { ela mesma tem algum } \\
\text { problema repentino. Já } \\
\text { fez acompanhamento } \\
\text { para diferentes condições } \\
\text { clínicas. }\end{array}$ \\
\hline $\begin{array}{l}\text { Aventu- } \\
\text { rina }\end{array}$ & Viúva & $\begin{array}{l}\text { Cuida da casa e, eventualmente, auxilia no } \\
\text { cuidado ao neto. }\end{array}$ & 48 & $\begin{array}{l}\text { Acompanhamento para } \\
\text { diabetes, dores abdominais } \\
\text { frequentes, ginecologia e } \\
\text { quaisquer problemas de } \\
\text { saúde que venha a sentir. }\end{array}$ \\
\hline Rubi & Casada & $\begin{array}{l}\text { Cuida da casa, de dois filhos ainda crianças e } \\
\text { de dois netos (bebês). }\end{array}$ & 40 & $\begin{array}{l}\text { Dores estomacais, } \\
\text { ginecologia e quaisquer } \\
\text { problemas de saúde que } \\
\text { venha a sentir. }\end{array}$ \\
\hline
\end{tabular}

Fonte: As autoras.

\section{Os sentidos da saúde segundo usuárias da ESF}

Canguilhem (2005) defende que o corpo é um dado - já que se constitui como efeito singular de componentes genéticos - e um produto, na medida em que sua inserção e modo de vida num meio específico contribuem para modificar sua estrutura morfológica e singularizar suas capacidades. Essa combinação paradoxal resulta num conjunto de poderes que podem ser reconhecidos, avaliados e testados pelo indivíduo que o vive.

Ao dizer o que entendem ser saúde, as entrevistadas apresentam uma combinação paradoxal, a que Canguilhem (2005) se refere. Ao mesmo tempo em que a definem como a ausência de doença, também a associam a um estado de difícil explicação, porque abarca a capacidade de produzir uma vida boa, segundo valores singulares. Tais definições, juntamente a um espectro de compreensões que delas derivam, estão imbricadas e foram organizadas em dois eixos temáticos, cada qual construído a partir de dois núcleos de sentido. O primeiro eixo, denominado 'Saúde como potência absoluta ou ausência de doença', compreende os núcleos de sentido: Saúde e bem-estar; e medicalização da saúde. Já o segundo eixo, intitulado 'Saúde como capacidade de criação', abarca os núcleos de sentido: saúde e risco de adoecimento; a saúde experimentada e o cuidado criativo.

\section{Saúde como potência absoluta ou ausência de doença}

\section{Saúde e bem-estar}

Algumas entrevistadas associavam saúde à ausência de doenças, ao mesmo tempo em que atribuíam à primeira o poder de produção de um estado 
análogo àquilo que a Organização Mundial da Saúde (OMS, 1978) define como completo bem-estar biopsicossocial. Ágata, por exemplo, afirma: “Para mim, ter saúde é não precisar procurar o médico e é ser feliz todos os dias".

Caponi (2009) lembra que a definição de saúde difundida pela OMS já foi bastante criticada em função de sua excessiva abrangência. A autora acrescenta que a maior dificuldade do conceito reside na sua tendência a legitimar valores próprios a um projeto societário que julga positivamente a capacidade laboral (requisito primeiro para o exercício do constante consumo de bens e serviços). Ao mesmo tempo, valoriza o controle dos excessos (com exceção do consumismo). Consequentemente, o conceito da OMS exclui as pessoas que não se adaptam ou não respondem adequadamente a essas condições. Assim, qualquer experiência de mal-estar que prejudique a capacidade produtiva passa a ser considerada problema de saúde.

É nesse sentido que Angelita considera que “(...) sem saúde não se faz nada. Preciso me manter saudável, porque preciso trabalhar, cuidar dos filhos". Na mesma direção, Oliveira et al. (2015) apontam que grande parte dos usuários da ESF associa saúde com capacidade laboral e reconhecem o tratamento apenas em sua dimensão curativa, considerando-o um obstáculo a ser transposto. Consequentemente, a doença é vista como evento estranho à vida, o que pode ser compreendido pela leitura que Lefève e Benaroyo (2015) fazem da obra de Canguilhem. Segundo os autores, ao tomar a saúde pública como objeto e ao empreender processos de classificação do normal e do patológico pautados em médias populacionais, a medicina passa a ser vista como técnica de normalização, produzindo certa negação do fato de que a doença faz parte da vida. Dessa negação deriva um quadro de obsessão coletiva pela saúde perfeita.

Na mesma direção, para Caponi (2009, p. 71), o “completo bem-estar biopsicossocial" parece supor a possibilidade de uma existência sem angústias, erros ou fracassos. Consequentemente, a doença acaba por ser vivida como um crime ou castigo, balizada pelo raciocínio médico, autorizado a delimitar os limites do estado saudável. É encarnando potenciais criminosas da saúde, que algumas usuárias entrevistadas 'confessam' que não estão fazendo exercício físico regularmente ou que, às vezes, 'desobedecem' a dieta para comer alimentos gordurosos.

Essa tendência de avaliação de comportamentos ou de compreensão de quaisquer problemas humanos a partir de uma lógica médica é chamada por Conrad (2007) de medicalização. Trata-se de um processo complexo que pode ter conotações éticas tanto positivas como negativas, sendo protagonizado por diferentes atores sociais. Sob o predomínio da medicalização, é inevitável que a doença ou aquilo que pode ser corrigido pela medicina seja tomado como referência para a compreensão do que viria a ser a saúde. O completo 'bemestar' perde, então, sua abrangência e passa a ser traduzido pela ausência de 
quaisquer doenças, como pode ser ilustrado por Coralina: "Acho que ter saúde é não ter nenhuma doença".

Uma das possíveis consequências desse tipo de construção subjetiva é a naturalização das negligências do Estado para com o cuidado à saúde da população, pois se investe mais em normalizar condutas individuais do que em transformar condições perversas de existência (Caponi, 2009). Acerca de tais condições, próprias a periferias como aquela em que vivem as pessoas entrevistadas, chamou a atenção o fato de que, embora sejam reconhecidas e criticadas, não são associadas aos problemas de saúde. Em duas ocasiões, entrevistadas disseram, por exemplo, que a pista de caminhada era perigosa, sendo preferível andar pelas calçadas de ruas mais movimentadas, suportando barulho e poluição. O dever de caminhar mostrava-se tão naturalizado quanto o descuido do Estado para com a segurança pública.

Assim, considerada como uma obrigação individual, a saúde se expressa, na perspectiva das entrevistadas, a partir da incorporação de hábitos saudáveis, como alimentação com baixos teores de gordura e açúcar, consumo mais racional de carboidratos e exercícios físicos. Trata-se de um tipo de conhecimento sobre hábitos saudáveis, adquirido pelo uso generalizado de diferentes meios de comunicação, mas também pela ampliação do acesso à ESF. A abrangência e intensificação da oferta de cuidados são operacionalizadas por profissionais formados a partir do paradigma biomédico hegemônico, que atuam em serviços cujo investimento na ampliação dos recursos não medicalizantes e da educação em saúde costuma ser baixo (Tesser, Poli Neto e Campos, 2006).

Sabe-se que a implantação da ESF buscava tencionar o modelo biomédico, mas não se pode desconsiderar o contexto sociocultural em que ela se desenvolve. Diferentemente do que se sonhava no momento de sua implementação, quando o país vivia um processo de redemocratização e reconstrução do aparelho estatal, a política em que o SUS tenta se sustentar hoje é o neoliberalismo e o consequente esvaziamento do Estado. Este esvaziamento incide no campo da saúde por meio dos discursos sobre o risco (e, mais recentemente, da 'suscetibilidade') e da imposição moral de que os indivíduos se responsabilizem pelo cuidado da própria saúde.

\section{Medicalização da saúde}

Rose (2007) ajuda a compreender essa situação apontando que o processo de medicalização gera o interesse da sociedade pelos fenômenos bioquímicos e genéticos. Desse modo, os pacientes abandonam uma postura de passividade frente ao médico para tomarem o lugar daqueles que reivindicam informações sobre sua doença e todas as formas de tratamento possíveis. Trata-se de uma nova condição que lhes serve como um passaporte para a cidadania. Cidadania esta que passa a ser definida e vivida de forma restrita, traduzindo-se em ape- 
nas duas representações ligadas ao campo da saúde: deveres individuais para com o próprio corpo e direito ao acesso às mais altas tecnologias de tratamento.

A esse respeito, Santos et al. (2014) problematizam o lugar atribuído à tecnologia diagnóstica, apontando, por exemplo, que a autopercepção corporal dos idosos participantes de sua pesquisa mostrara-se completamente secundária àquilo que os exames indicavam sobre suas condições de saúde. Na mesma direção, para todas as pessoas entrevistadas nesta pesquisa, a saúde é, prioritariamente, atestada a partir dos instrumentos médico-tecnológicos capazes de identificar e objetivar problemas no corpo humano. Trata-se de uma aposta tão grande na medicina diagnóstica, que quando os exames não apontam nenhum problema, o primeiro movimento é desacreditar de seus resultados e procurar outro serviço cuja aparelhagem funcione melhor. Tal como é possível observar no trecho a seguir, Cristal valoriza seus incômodos e sensações corporais, mas a única estratégia para compreendê-los ou significálos é o uso da tecnologia médica:

Eu tinha vontade de fazer um exame completo, um check up. Eu faço aquele exame que cola umas coisinhas aqui (aponta para a região dos seios), faço esse exame e não dá nada, mas eu sinto alguma coisa. Também tenho que fazer um exame da coluna porque teve um dia que eu tive uma queda, parece que tá apertando meu coração. Tem hora que eu fico ansiosa, sufocada, parece que tá me apertando por dentro. Mas a doutora não passa, não sei o que fazer, o jeito é procurar outro hospital pra ver essas coisas (...). Eu queria um exame do corpo todo porque eu sinto muita coisa. Faço o preventivo aqui e não dá nada, mas e o que a gente sente? (...). Muita gente que faz não dá nada, aí vai para outra parte, porque não tem fé aqui.

Pesquisas mostram que o objetivo de garantia de acesso da população aos cuidados em saúde vem sendo alcançado pela implantação da ESF, ainda que com importantes limitações. Estas não passam despercebidas pelos usuários que, cientes de seus direitos, reclamam por melhor acesso a exames, continuidade do cuidado e respeito do médico para com suas queixas (Oliveira et al., 2015; Viegas, Carmos e Luz, 2015; Giovanella et al., 2013; Ferrer et al., 2012). Trata-se, portanto, de um trabalho de favorecimento da construção da cidadania que ainda não é garantida a todos os brasileiros. As pessoas entrevistadas também se sentem legitimadas para exigir seus direitos, tal como assegura Rubi: “Somos nós que pagamos esses exames, porque pagamos INPS (Instituto Nacional de Previdência Social) e essas coisas! (...) Se o caso dela não se resolver, vou chamar o RJTV [telejornal]. Se isso não funcionar, teremos que chamar a polícia".

Observa-se, contudo, que os direitos exigidos dizem respeito, hegemonicamente, ao poder de consumo de recursos médico-tecnológicos que evi- 
tam ou curam o adoecimento, tal como comentam Tesser, Poli Neto e Campos (2010, p. 3618). Tais recursos são associados à pesquisa e à divulgação dos fatores de risco à saúde, que disseminam a crença de que é possível controlar o envelhecimento e as variadas formas de impotência experimentadas ao longo da vida, empreendendo o que os autores chamam de "medicalização do futuro".

\section{Saúde e risco de adoecer}

Depara-se, assim, com uma situação paradoxal, cujos polos são marcados, por um lado, pelas vantagens do acesso à informação e meios de tratamento e, por outro, pela submissão a regras de bem viver e pela fantasia de controle dos limites inerentes ao corpo humano. Coralina expressa bem esse paradoxo: "Eu sempre faço exame porque meu pai era diabético, tinha problema de coração, a família do meu pai toda tinha problema de coração e era diabética. Então, sempre estou me cuidando, sempre fazendo exame, indo ao médico".

O cuidado, ainda que restrito ao campo médico, certamente contribui para que Coralina usufrua melhor de seus recursos pessoais e da própria vida, mas, não se constatar isso sem reconhecer o caráter fantasioso que acompanha os esforços de prevenir todos os infortúnios do corpo.

Nesse contexto, reconhece-se que a tentativa de controle dos riscos de adoecer, muitas vezes, oportuniza experiências de vida que ultrapassam os limites do campo médico. Assim, para Pérola, as atividades feitas junto à educadora física da $\mathrm{CF}$, voltadas à prevenção de hipertensão, proporcionam também a convivência com pessoas diferentes dela, contribuindo com a socialização e a diversificação de experiências de vida. Rosa faz comentários no mesmo sentido, descrevendo, longamente, os benefícios que festas e passeios com os amigos proporcionam à sua saúde. Entretanto, é interessante notar que, mesmo essa forma de cuidado, aparentemente não cooptada pela lógica da medicalização, é atribuída por Rosa à orientação da psicóloga, com quem fizera psicoterapia por muitos anos. Ela não se refere a uma descoberta ou a uma construção singular, conquistada em conjunto com a profissional, mas a uma espécie de prescrição altamente eficaz.

Cumpre observar, contudo, que a associação entre experiências que promovem saúde e orientações e prescrições de especialistas também parece ser consequência do fato de que, para todas as entrevistadas, a preocupação com a saúde fora despertada, invariavelmente, quando esta lhes faltou. Jade ilustra bem essa questão:

Na verdade, a gente nunca pensa em cuidar não é? Porque tem trabalho, filhos, a gente vai deixando pra lá... Foi quando eu fiquei doente que vi que o corpo não aguenta... Aí, você tem que dar uma parada e ver o que está acontecendo. 
Essa observação remete a Canguilhem (2005), para quem as doenças humanas não se limitam às disfunções orgânicas ou limitações físicas, pois são, propriamente, dramas nas histórias dos sujeitos. Estes se colocam ao homem não por castigo ou destino, mas simplesmente porque existem no mundo e se impõem a qualquer ser que faz julgamentos de valor sobre si mesmo e sobre a vida. Assim, é o drama julgado negativamente e não (ou não apenas) a informação objetiva sobre a normalidade dos estados vitais que produz a preocupação com a manutenção destes.

Vale lembrar que julgamentos de valor são influenciados pelos ideais que predominam numa sociedade e, assim sendo, deve-se admitir a inexistência de critérios objetivos e precisos que diferenciam o saudável do patológico. Portanto, a saúde só pode ser pesquisada tendo como referência sua dimensão relacional. Na relação com o meio, o sujeito saudável é aquele que possui recursos necessários para responder às suas exigências e surpresas, assim como para provocar-lhe transformações. A saúde permite que o meio seja sempre valorado e significado pelo indivíduo, de tal modo que ela é entendida como uma “(...) maneira de abordar a existência com a sensação não apenas de possuidor ou portador, mas também, se necessário, de criador de valor, de instaurador de normas vitais." (Canguilhem, 1978, p. 163).

Essa possibilidade de criação de novos valores e de contestação de normalidades consolidadas mostrou-se presente nas entrevistadas, ainda que não tenha sido predominante. É sobre essas representações, que fazem algum desvio no curso de sentidos produzidos em torno da medicalização, mesmo que a eles conectadas, que serão tratados a seguir.

\section{A saúde como criação}

\section{A saúde experimentada e o cuidado criativo}

O lugar de verdade atribuído ao diagnóstico e à prescrição médica pelos sujeitos da pesquisa, embora abrangente, não está imune a questionamentos e, tampouco, se manifesta de forma homogênea e constante. Assim, embora utilizando um linguajar médico, as entrevistadas contestam certas colocações dos especialistas, criam suas estratégias de cuidado ou recriam aquelas prescritas pelos profissionais, tal como indica o trecho a seguir:

Acho que também estou com problema de tireoide, porque tenho tido dificuldade para engolir. A médica disse que não era nada, mas é, sim! Quem tem que saber sou eu. Sou eu quem engole as coisas, tenho dificuldade até de beber água (Rubi).

Canguilhem (2005) enfatiza a importância da experiência do doente, indissociável do conhecimento que hoje se possui. Tal autor ressalta que a me- 
dicina só existe porque há pessoas que sofrem algum incômodo, que têm sua vida contrariada. Ela não pode ser entendida como um conjunto de procedimentos criados para informar aos indivíduos que eles estão doentes e, nesse sentido, o médico deve permitir que o paciente o reconheça como “(...) um exegeta, antes de vê-lo como um reparador. (...)” (Canguilhem, 2005, p. 45). $\mathrm{O}$ autor não desmerece a importância do diagnóstico, reconhecendo-o como um recurso objetivo o qual permite que o paciente não se oriente apenas pelas suas angústias ou sua imaginação. O problema reside no fato de que o diagnóstico, frequentemente, reduz o doente à patologia ou a um objeto de classificação, negando tais experiências subjetivas (Lefève e Benaroyo, 2015).

Considerando que grande parte da tecnologia em saúde é aplicada em órgãos localizados num corpo, cuja totalidade não costuma despertar interesse para o profissional, atribui-se especial destaque a formas de construção de conhecimento que não admitem a existência de um saber cindido da experiência do vivente. Turquesa, ainda que valorize a tecnologia diagnóstica, sinaliza que a experiência lhe garante certa independência: "Quanto à minha saúde, eu não sou uma pessoa hipertensa, sempre procurei me cuidar de uma forma saudável, quando eu não estou me sentindo bem, meu corpo avisa". Coutinho e Souza (2012) encontraram resultados semelhantes ao identificar que usuários em tratamento de hipertensão, apesar de demonstrarem pouco conhecimento sobre este quadro clínico, puderam explicá-lo tendo como referência o impacto do problema sobre seus corpos.

Acerca da integração entre experiência e prescrição médica, é interessante observar também a narrativa de Pérola. Nela, observa-se que, embora soberano, o saber médico, muitas vezes, é submetido a adaptações ou é substituído por conhecimentos e estratégias de cuidado advindos da vida social:

(...) Eu até pensei que fosse ficar com alguma coisa de sistema nervoso. (...) Quando meu pai ficou mal, o médico até passou esse tal de diazepam, que usavam antigamente. (...). Mas a mãe do meu ex-marido falou 'não toma isso não', bebe um chá porque se você começar a tomar vai ficar dependente. Por isso não tomei. Fazia chá, (...) e passava a ler livros. (...) comecei a comprar livros, passei a ler todos eles, pois você melhora o português também. Eu falei para o meu filho ler também e procurar a biblioteca da escola. Hoje eu leio, ele lê e, às vezes, estamos lendo o mesmo livro. (...)

Eu não escrevia na internet porque eu ficava com medo. Estudei só até o quinto ano. Não escrevia, não mandava mensagem porque não sabia se estava certo. Com a leitura, fiquei melhor na escrita. (...). Para o meu sistema nervoso eu levo um livro na bolsa! 
Foi interessante notar que Pérola afirmava ter predileção pelos livros do padre Marcelo, mas não se referia a conteúdos específicos desses escritos. Pareceu-nos que sua estratégia terapêutica se situava mais no ato de ler do que naquilo que lia. Ela descobriu um modo pessoal de cuidar do seu 'sistema nervoso', o que também facilitou sua inserção no mundo digital. Nesse caso, a doença do pai e a recusa ao remédio tranquilizante acabaram por se desenrolar numa diminuição da exclusão social por ela vivida.

A “fabricação" (Cecílio, 2012, p. 284) dessa estratégia terapêutica lembra aquilo que Winnicott (1975, p. 95) entende por criatividade - "um colorido de toda a atitude com relação à realidade" - e não a concretização de projetos bem-sucedidos ou obras de arte. Para ele, "é através da apercepção criativa, mais do qualquer outra coisa, que o indivíduo sente que a vida é digna de ser vivida (...)" (Winnicott, 1975, p. 95). Nesse sentido, saúde e criatividade são correlatas, mas a primeira "(...) é tolerante com a doença" (Winnicott, 2005, p. 15). O indivíduo saudável é aquele que pode (porque tem algum grau de confiança na vida) adoecer, deprimir-se, entrar em contato com seus conteúdos arcaicos e dolorosos. Na mesma medida, é aquele que consegue viver cada etapa de seu desenvolvimento, experimentando seus infortúnios, sem negá-los e, tampouco, fixar-se neles. A adolescência e o estado de confusão e dúvida impostos pela definição sexual, bem como a integração da própria sexualidade são bons exemplos disso. Portanto, a saúde diz respeito à sensação que as pessoas têm de que “(...) estão vivendo a própria vida, assumindo responsabilidade pela ação ou pela inatividade, e sejam capazes de assumir os aplausos pelo sucesso ou as censuras pelas falhas. (...)" (Winnicott, 2005, p. 10).

Rosa exemplifica bem essas afirmações quando comenta algumas mudanças identificadas em sua filha, uma moça de 24 anos, com quadro de déficit intelectual e importante dependência para a realização de atividades básicas da vida:

Parece que Amanda entrou na adolescência do ano passado para cá. Hoje em dia ela está questionando, teimando... Antigamente, ela aceitava tudo. Mas ela melhorou, está ótima... Outro dia, mandei que fizessem francesinha na unha dela. Ela foi para um aniversário e no dia seguinte tirou todo o esmalte. Quando questionei, falou que não queria esmalte transparente... (...). Enquanto tirava esmalte, ela me disse: 'você não me perguntou qual cor eu queria!' Ela está terrível! Está amadurecendo. Gosto disso porque está diferente. Antes era horrível, se dissesse: "senta aí", ela sentava e ficava. (...)

Teimosia, postura questionadora e insubordinação são expressões entendidas por Rosa como sinais de amadurecimento, mesmo que a filha já tenha mais de vinte anos e ainda dependa dela para se locomover na cidade, fazer 
operações matemáticas simples e organizar seu cotidiano. Embora incômodas, as marcas da adolescência são bem recebidas pela entrevistada, parecendo provocar, também nela, novos posicionamentos no seu exercício de maternidade.

Coelho e Almeida Filho (1999) destacam que, para Canguilhem, saúde implica poder desobedecer, produzir ou acompanhar uma transformação, adoecer e sair do estado patológico. Rosa expressa essa ideia, ao associar saúde à disposição para viver a vida, enfrentando suas demandas, inclusive aquelas derivadas da doença.

Na mesma direção, Winnicott (2005) discorda de concepções que associam saúde à precocidade, ou agilidade em viver as etapas da vida. De forma bastante coloquial, ele defende: “(...) é saudável ter seis anos aos seis anos de idade, e dez aos dez." (Winnicott (2005, p. 6). Além disso, assim como Canguilhem (1978), a teoria winnicottiana não admite a ideia de saúde como ausência de doença (que para os interesses do autor relaciona-se à doença psiconeurótica) e propõe que se pense “(...) em termos de liberdade dentro da personalidade, de capacidade para ter confiança e fé, (...), de liberdade em relação à autoilusão e também de algo que tem mais a ver com riqueza do que com a pobreza enquanto qualidade da realidade psíquica pessoal" (Winnicott, 2005, p. 9).

Por meio do relato de Rosa, é possível vislumbrar esse tipo de liberdade também quando narra seu projeto de fazer faculdade de educação física, lembrando-se da vida de esportista que abandonara quando se casou. Com a ajuda da educadora física da Clínica da Família, constatou que suas dores crônicas não são um empecilho para o ingresso na faculdade; pelo contrário, podem ser beneficiadas com o estudo acerca do corpo humano e com os exercícios vinculados ao curso de graduação.

Há que se destacar, contudo, que mesmo associando saúde à disposição, nenhuma das entrevistadas mencionou algum tipo de disponibilidade para investir em respostas coletivas às adversidades impostas pela sociedade e pelos serviços de saúde. Assim como identificado nos estudos de Viegas, Carmo e Luz (2015), Silva, Andrade e Bosi (2014) e Ferrer et al. (2012), foram vários os relatos de dificuldade em realizar exames, consultar especialistas no serviço público ou ter a continuidade do tratamento. Não houve, porém, nenhuma iniciativa de associação entre os usuários para reivindicar melhoria no acesso, por exemplo. Há o reconhecimento do direito à atenção em saúde pública, mas este é exigido individualmente, sem busca de apoio coletivo. Diante da dificuldade de fazer exames ou da insatisfação com o atendimento na unidade de saúde da família que a acompanha, Cristal, por exemplo, afirma que gostaria de ter dinheiro para pagar consultas particulares e de procurar um hospital, enquanto que Rubi chama a imprensa. Nenhuma delas participa de Conselhos de Saúde ou considera a possibilidade de contar com esse tipo de arranjo.

Observa-se, assim, que em consonância com os valores da sociedade contemporânea, a disposição ou a saúde é desejada na esfera individual. Precisa- 
se de saúde para trabalhar. Reconhece-se saúde no corpo bonito, forte, como mostra o relato a seguir:

Sempre trabalhei! Desde nova! (...) Eu era uma mulher sadia. Toda vida fui forte, quer dizer, bem feitinha, não tinha essa barriga. Hoje tenho essa inchação, porque fiz cirurgia. (...) Não sou mais normal como antes. Eu era uma mulher forte, disposta (Aventurina).

Segundo alguns autores, os homens reconhecem-se hoje como "empreendedores de suas próprias vidas, atores centrais da sociedade e sujeitos em busca do máximo de prazer" (Enriquez e Carreteiro, 2013, p. 75). Sustentados numa ética individualista, o ser humano delega qualquer mal-estar à incapacidade individual de viver ou ao erro do outro (seja ele o Estado, o empregador ou outra instância ou ator social), a quem se deve, também individualmente, cobrar (Santos, 2001). Tamanha responsabilidade induz ao anseio por uma saúde que produza sucesso e bem-estar. Estes, porém, quando obstruem o sentimento de que a vida é fruto de uma criação singular, que admite a derrota e a fraqueza, acabam por impedir a fruição da saúde, entendida aqui como capacidade normativa, possibilidade de criação.

\section{Considerações finais}

Ao desenvolver entrevistas em profundidade, com um número pequeno de pessoas, foi possível ter acesso a construções de sentido bastante profundas e, ao mesmo tempo, expressivas, de certa realidade sociocultural, ainda que não haja uma amostra representativa. Contudo, é preciso considerar o fato de que todos os sujeitos de pesquisa eram do gênero feminino. Por um lado, isso garantiu certa condição de homogeneidade, mas, por outro, restringiu a compreensão de sentidos próprios ao mundo masculino. Não cabe, no escopo deste trabalho, uma discussão sobre gênero e saúde, mas não se pode furtar da suposição de que as indicações feitas pelos profissionais podem ser fruto de alguns fatores, tais como: predomínio de associações do cuidado como uma responsabilidade feminina, maior presença de mulheres do que de homens nas unidades de saúde (Martha et al., 2011), menor acesso das mulheres ao mercado de trabalho e, consequentemente, facilidade de acesso a elas em suas casas.

A utilização do método das narrativas de vida propiciou a emergência de diferentes sentidos acerca da saúde, abarcando as contradições próprias à condição humana. Observou-se que 'estar saudável' tornou-se um imperativo da sociedade contemporânea. Nesse contexto, os sujeitos veem-se obrigados a viver uma potência absoluta a ser conquistada por meio de bons hábitos e acesso à tecnologia médica. Entre os extremos marcados pela saúde como 
negativo da doença e como energia inesgotável, contudo, encontram-se, também, sentidos associados à capacidade de construir respostas singulares aos infortúnios da vida.

Com Canguilhem (1978), defendeu-se que saúde diz respeito à capacidade normativa, à tolerância às transformações impostas pela vida, entre as quais se incluem as doenças. Tal capacidade, entretanto, não deriva de uma espécie de geração espontânea, pois depende de condições básicas para desenvolver-se. Mesmo Winnicott (2005), o qual concebe criatividade (e, consequentemente, saúde) como uma capacidade inata, insiste que, sem um ambiente social que facilite seu aparecimento, ela mantém-se aprisionada, comprometendo a espontaneidade dos sujeitos nas suas relações com o mundo e consigo.

Os indivíduos vivem num contexto de dificuldade de acesso não apenas a serviços de saúde, como também à educação e cultura, problemas de saneamento básico, carga excessiva de trabalho, violência urbana, entre outras injustiças sociais. Nesse cenário, podem até conseguir se submeter a algumas regras de prevenção do risco de adoecer, mas são restritas suas possibilidades de criação de modos singulares de fruição da vida ou de experimentação da saúde. Assim, considera-se que intervenções sobre a conduta individual e tentativas de normalização da saúde podem contribuir para a diminuição de algumas condições clínicas prejudiciais. Contudo, estas intervenções tornamse perniciosas quando estão a serviço da desresponsabilização do Estado para com condições sociais e sanitárias que constituem o fundamento de qualquer possibilidade de vida saudável.

Na sociedade contemporânea, a imposição da constante competição, o culto à imagem e a massificação do desejo são importantes fatores que obscurecem as possibilidades de reconhecimento dos traços singulares dos sujeitos. Busca-se, vertiginosamente, viver 'a vida do outro', aquele cuja felicidade estampada nas redes sociais reproduz a negação do mal-estar. Cegos às nossas dores e ao nosso potencial para delas cuidar, os indivíduos acabam por demandar dos especialistas as intervenções e regras capazes de incluí-los naquilo que se considera como 'qualidade de vida'. Para fazer resistência a esse processo que facilita a produtividade, mas restringe singularidade, concorda-se com Figueiredo (2014, p. 28), para quem a participação criativa dos indivíduos nas diversas áreas de vida deve ser tomada como “(...) um direito fundamental à saúde". Acredita-se que, ainda que pelas margens e arestas, é fundamental que se esteja atento às possibilidades de operacionalização desse direito no SUS. 


\section{Colaboradores}

Lilian Miranda responsabilizou-se pela elaboração da pesquisa, orientação, coleta de dados, análise das informações, redação e revisão crítica do artigo. Luciana Janeiro Silva responsabilizou-se pela elaboração da pesquisa, coleta de dados, análise das informações e revisão crítica do artigo. Yasmim Furtado de Souza participou da revisão bibliográfica para a pesquisa, bem como da revisão crítica.

\section{Financiamento}

Este artigo é fruto de pesquisa financiada pela Faperj-APQ1 e contou com participação de bolsista de Iniciação Científica, Bolsa Pibic-Fiocruz.

Não há conflitos de interesse.

\section{ENTRE AUSENCIA DE ENFERMEDAD Y CUIDADO POSIBLE: LA SALUD SEGÚN USUARIOS DE LA ESTRATEGIA SALUD DE LA FAMILIA}

Resumen El artículo presenta sentidos que usuarias de la Estrategia de Salud de la Familia atribuyen a la salud y su relación con el cuidado. Se utilizó el método cualitativo, tomándose como referencial teórico las discusiones de Canguilhem y Winnicott acerca de la noción de salud, así como apuntes sobre medicalización de la vida. El trabajo de campo fue desarrollado por medio de entrevistas en profundidad entre mayo y julio de 2015 con usuarios de la Estrategia de Salud de la Familia y tratado por el análisis hermenéutico. La salud, relacionada tanto a la ausencia de enfermedad y al completo bienestar, cuanto a la disposición para enfrentar los sufrimientos inherentes a la vida. Coexisten la confianza incondicional en la tecnología médica y la apuesta en modos de cuidados intuitivos u oriundos de relaciones sociales. El servicio de salud contribuyó con el acceso al tratamiento y, simultáneamente, refuerza la apuesta en la prevención de todos los infortunios del cuerpo, así como la idea de que el derecho a la salud es correlativo a la responsabilidad individual de mantenerla perfecta. En una cultura marcada por el individualismo y competitividad, individuos que viven en contextos de profundas injusticias sociales se someten a reglas de prevención del riesgo de enfermarse, pero son restrictas sus posibilidades de creación de modos singulares de fruición de la vida.

Palavras clave salud; cuidado en salud; usuarios de servicios de salud. 


\section{Referências}

AZEVEDO, Creusa S. A abordagem de narrativas de vida como um caminho de pesquisa em saúde. In: AZEVEDO, Creuza S.; SÁ, Marilene C. (org.). Subjetividade, gestão e cuidado em saúde: abordagens da psicossociologia. Rio de Janeiro: Editora Fiocruz, 2013. p. 131-154.

BERTAUX, Daniel. Les récits de vie. Paris: Éditions Nathan, 1997.

BEZERRA JUNIOR, Benilton. O normal e o patológico: uma discussão atual. In: SOUZA, Alicia N.; PITANGUY, Jaqueline (orgs.). Saúde, corpo e sociedade. Rio de Janeiro: Editora UFRJ, 2006. p. 91-109.

BIRMAN, Joel. Os sentidos da saúde. Physis: Revista de Saúde Coletiva, Rio de Janeiro. v. 9, n. 1, p. 7-12, 1999.

BRASIL. Ministério da Saúde. DAB. Disponível em: <http://dab.saude.gov.br/portaldab/ historico_cobertura_sf.php $>$. Acesso em: 3 jan. 2017.

BRASIL. Ministério da Saúde. Política Nacional de Atenção Básica. Brasília, Ministério da Saúde, 2012. 110 p.

CAMPOS, Gastão W. S. Reforma da Reforma: repensando a saúde. 3. ed. São Paulo: Hucitec, 2006.

CANGUILHEM, Georges. O normal e o patológico. Rio de Janeiro: Forense-Universitária, 1978.

CANGUILHEM, Georges. Escritos sobre a medicina. Rio de Janeiro: Forense Universitária, 2005.

CAPONI, Sandra. A saúde como abertura ao risco. In: CZERESNIA, Dina; FREITAS, Carlos M. (orgs.). Promoção da saúde: conceitos, reflexões, tendências. Rio de Janeiro: Editora Fiocruz, 2009. p. 59-82.

CECÍLIO, Luiz C. O. Escolhas para inovarmos na produção do cuidado, das práticas e do conhecimento: como não fazermos 'mais do mesmo'. Saúde e Sociedade, São Paulo, v. 21 n. 2, p. 280-289, 2012.

CECÍLIO, Luiz C. O. et al. (orgs.). Os mapas do cuidado: o agir leigo na saúde. São Paulo: Hucitec; Fapesp, 2014.

COELHO, Maria T. A. D.; ALMEIDA-FILHO, Naomar. Normal-patológico, saúde-doença: revisitando Canguilhem. Physis: Revista de Saúde Coletiva, Rio de Janeiro, v. 1, n. 1, p. 13-36, 1999.

CONRAD, Peter. The medicalization of society: on the transformation of human conditions into treatable disorders. Baltimore: Jonh Hopkins University Press, 2007.

COUTINHO, Fernanda H. P.; SOUZA, Islância M. C. Percepção dos indivíduos com hipertensão arterial sobre sua doença e adesão ao tratamento medicamentoso na estratégia de saúde da família. Revista Baiana de Saúde Pública, Salvador, v. 5, n. 2, p. 397-413, 2012.

CZERESNIA, Dina. O conceito de saúde e a diferença entre promoção e prevenção. In: CZERESNIA Dina; FREITAS, Carlos M. (orgs.). Promoção da saúde: conceitos, reflexões, tendências. Rio de Janeiro: Editora Fiocruz, 2009. p. 43-58.

DENZIN, Norman K.; LINCOLN, Yvonna S. Handbook of qualitative research. Thousand Oaks: Sage; 1994.

ENRIQUEZ, Eugène; CARRETEIRO, Tereza C. Reconhecimento e resistências nas sociedades contemporâneas. In: AZEVEDO, Creuza S.; SÁ, Marilene C. (orgs.). Subjetividade, Gestão e Cuidado em Saúde: abordagens da psicossociologia. Rio de Janeiro: Editora Fiocruz, 2013, p. $75-88$.

FERRER, Ana L. et al. Avaliação de estratégias inovadoras na organização da Atenção Primária à Saúde. Revista de Saúde Pública, São Paulo, v. 46, n. 1, p. 43-50, 2012. 
FIGUEIREDO, Luis C. Cuidado e saúde: uma visão integrada. In: FIGUEIREDO, Luis C. Cuidado, saúde e cultura: trabalhos psíquicos e criatividade na situação analisante. São Paulo: Escuta, 2014. p. 9-30.

GADAMER, Hans-Georg. Verdade e método: traços fundamentais de uma hermenêutica filosófica. Petrópolis: Vozes, 1997.

GIOVANELLA, Lígia et al. Avaliação da atenção básica pela perspectiva dos usuários: adaptação do instrumento EUROPEP para grandes centros urbanos brasileiros. Ciência \& Saúde Coletiva, Rio de Janeiro, v. 18, n. 1, p. 103-114, 2013.

HORKHEIMER, Max; ADORNO, Theodor. Conceito de iluminismo. Coleção Os Pensadores. São Paulo: Editora Nova Cultural Ltda, 1989.

LEFÈVE, Céline; BENAROYO, Lazare. Georges Canguilhem: se projeter em situation de malade. In: LEFÈVE, Céline; BENAROYO, Lazare; WORMS, Frédéric (orgs.). Les classiques du soin. Paris: Presses universitaires de France, 2015. p. 89-104.

LÉVY, André. Ciências clínicas e organizações sociais: sentido e crise de sentido. Belo Horizonte: Autêntica/Fumec, 2001.

LOYOLA, Maria A. Representações sociais e saúde. Ciência \& Saúde Coletiva, Rio de Janeiro, v. 18, n. 1, p. 2.176-2.176, 2013.

LUZ, Madel T. Fragilidade social e busca de cuidado na sociedade civil hoje. In: PINHEIRO, Roseni; MATTOS, Ruben A. (orgs.). Cuidado: as fronteiras da integralidade. Rio de Janeiro: Cepesc-IMS-Abrasco, 2013. p. 11-22.

MARTHA, Sara N. et al. Programa Saúde da Família sob a visão do usuário. Salusvita, Bauru, v. 30, n. 3, p. 159-177, 2011.

OLIVEIRA, Edward M. et al. Determinantes sócio-históricos do cuidado na Estratégia Saúde da Família: a perspectiva de usuários da área rural. Saúde e Sociedade, São Paulo, v. 4, n. 3, p. 901-913, 2015.
ONOCKO-CAMPOS, Rosana. Fale com eles! O trabalho interpretativo e a produção de consenso na pesquisa qualitativa em saúde: inovações a partir de desenhos participativos. Physis: Revista de Saúde Coletiva, Rio de Janeiro, v. 21, n. 4, p.1.269-1.286, 2011.

ORGANIZAÇÃO MUNDIAL DE SAÚDE. United Nations Children's Fund. Cuidados Primários de Saúde Alma-Ata. URSS: OMS, 1978.

PREFEITURA DO RIO DE JANEIRO. Portal da Secretaria Municipal de Saúde. Disponível em: <http://www.rio.rj.gov.br/web/sms>. Acesso em: 03 jan. 2018.

ROSE, Nikolas. Biopolitics in the Twenty-first Century. In: ROSE, Nikolas. The politics of life itself: biomedicine, power and subjectivity in the twenty-first century. Princeton: Princeton University Press, 2007. p. 9-40.

SANTOS, Boaventura S. Pela mão de Alice: o social e o político na pós-modernidade. São Paulo: Cortez, 2001.

SANTOS, Wagner J. et al. Avaliação da tecnologia das relações de cuidado nos serviços em saúde: percepção dos idosos inseridos na Estratégia Saúde da Família em Bambuí, Brasil. Ciência \& Saúde Coletiva, Rio de Janeiro, v. 19, n. 8, p. 3.441-3.450, 2014.

SILVA, Maria Z. N.; ANDRADE, Andrea B.; BOSI, Maria L. M. Acesso e acolhimento no cuidado pré-natal à luz de experiências de gestantes na Atenção Básica. Saúde em Debate, Rio de Janeiro, v. 38, n. 103, p. 805-816, 2014.

SOUZA, Elizabethe C. F. et al. Acesso e acolhimento na atenção básica: uma análise da percepção dos usuários e profissionais. Cadernos de Saúde Pública, Rio de Janeiro, v. 24, n. 1, p. 100-110, 2008.

TESSER, Charles D.; POLI NETO, Paulo; CAMPOS, Gastão W. S. Acolhimento e (des)medicalização social: um desafio para as equipes de saúde da família. Ciência \& Saúde Coletiva, Rio de Janeiro, v. 15, supl. 3, p. 3.615-3.624, 2010. 
VIEGAS, Ana P. B.; CARMO, Rose F.; LUZ, Zélia M. P. Fatores que influenciam o acesso aos serviços de saúde na visão de profissionais e usuários de uma unidade básica de referência. Saúde e Sociedade, São Paulo, v. 24, n. 1, p. 100-112, 2015.
WINNICOTT, Donald W. O conceito de indivíduo saudável. In: WINNICOTT, Donald Wood. Tudo começa em casa. São Paulo: Martins Fontes, 2005. p. 3-22.

WINNICOTT, Donald W. A criatividade e suas origens. In: WINNICOTT, Donald W. O brincar e a realidade. Rio de Janeiro: Imago, 1975. 